\title{
O APOIO NO DUPLO AUTÍSTICO NA CONSTRUÇÃO DO IMAGINÁRIO NO AUTISMO
}

e a identificação com duplos imaginários como pilares da constituição de uma imagem do corpo próprio, do surgimento do narcisismo e da construção de um ego no autismo.

Descritores: psicanálise; autismo; duplo; imaginário; ego.

\section{Marina Bialer}

\section{Introdução}

Através da análise dos dois primeiros livros autobiográficos de Donna Williams, é evidenciada a importância da invenção de identificações imaginárias com seus duplos autísticos, que ancoram a construção de processos identificatórios, de alienação ao pequeno outro semelhante, alicerçando a construção de uma imagem na qual o autista pode se espelhar para tecer o estofo de seu imaginário.

O recurso ao duplo pode ser extremamente importante, muitas vezes necessário, para que o autista possa encontrar uma solução para se relacionar com o mundo, saindo do isolamento autístico.

- Psicóloga. Doutora em Psicopatologia e Psicanálise pela Université Paris 7 Denis Diderot, Paris, França e doutora em Psicologia Clínica pelo Instituto de Psicologia da Universidade de São Paulo, São Paulo, SP, Brasil.

92 Estilos clin., São Paulo, v. 20, n. 1, jan./abr. 2015, 92-105. 
A relação identificatória com os duplos protege o autista, filtrando o que vem do exterior por intermédio destes, além deles se constituírem como bordas de investimento de gozo, cuja relação favorece a saída da inércia e a dinamização.

$\mathrm{O}$ alicerce do duplo permite ao autista se destacar do real e caminhar em direção a compensações no âmbito do imaginário. O laço com um duplo imaginário é uma construção do autista, fruto de um intenso trabalho psíquico que lhe permite encontrar neste outro um apoio que lhe auxilia a encontrar uma dinamização pulsional e uma regulação da economia de gozo.

O autista não pode recorrer à identificação primordial com o traço unário para se estruturar, mas Maleval (2009) propõe a possibilidade de uma identificação compensatória no campo imaginário, o que Frayssinet (2012) designa por identificação mimética com o duplo. O duplo autístico é, muitas vezes, imprescindível como apoio para uma alienação que pode alicerçar a construção da imagem do outro e de si próprio.

O exemplo de Donna Williams é particularmente interessante, dado que quando criança, era frequentemente rotulada de débil e caracterizada como uma autista de baixo-funcionamento. Entretanto, a partir da leitura de suas autobiografias podemos apontar importantes processos psíquicos complexos que se desenvolviam silenciosamente e que evoluíram até obter a constituição do estofo imaginário compensatório, que é o tema do presente artigo.

Abordaremos as várias identificações viabilizadas pelos principais duplos de Donna - Carol, Willie, Travel e Moggin -, que desembocam no surgimento de uma imagem do corpo próprio, no investimento narcísico e na concretização de um ego como produto destes processos identificatórios.

\section{O surgimento da imagem de um outro no espelho através do duplo autístico Carol}

Aos 5 anos de idade, após o encontro de Donna com uma menina chamada Carol, Donna toma uma decisão crucial para a sua vida: a decisão de querer viver no mundo de Carol, que se desdobra na decisão de querer sair do isolamento autístico e habitar o mundo.

Donna se identifica com a imagem de Carol, e copia dela comportamentos e modos de interagir com as outras pessoas. Após a separação da Carol "real", Donna inventa um duplo imaginário que ela designa Carol. Nesta etapa, a relação de Donna com a imagem refletida no espelho se torna uma relação de segurança e de confiança, dada a familiaridade e a previsibilidade do reflexo. 
Frente ao espelho, Donna "adentra" seus próprios olhos e toca a si mesma como a outra pessoa, e na imagem de si refletida pode ver e encontrar seu alter ego, Carol. Nesta etapa de espelhamento, a imagem de Carol tem, para Donna, vida própria, não sendo vivida como um reflexo, mas como um ego suplementar, fornecido por um duplo dela mesma.

A Carol imaginária surge no espelho da casa de Donna. Quando Donna olha para si mesma no espelho, encontra Carol. É no ponto de contato entre a imagem de Carol e a de si mesma que surge a porta de contato entre seu mundo autístico e o mundo compartilhado onde Carol vivia. O espelho se torna, desta forma, um ponto de borda, onde pode ser investido um gozo que estava sem localização por falta da crochetagem do gozo ao significante no autismo. Nas bordas do espelho entre Carol-duplo e Donna real, surge um espaço intermediário entre o mundo de Donna e o mundo da sua personagem imaginária (que era o mundo da sua própria imagem refletida via um duplo).

É interessante apontarmos que Donna relata suas tentativas frustradas de passar para o lado do espelho onde vê a imagem refletida, o que equivaleria a entrar no mundo compartilhado, mas fica presa do outro lado e encontra no olhar de Carol a mesma tristeza e sofrimento, em face de sua própria impossibilidade. É através do espelhamento da sua tristeza no olhar de Carol que Donna pode entrar em contato com a sua emoção. Neste sentido, podemos sublinhar a possibilidade de Donna ter acesso a si mesma na ressonância da sua vivência psíquica via Carol. Através desta personagem espelhada, Donna pode entrar em contato com a sua própria tristeza e sofrimento, o que lhe era inacessível sem a passagem pelo duplo-Carol.

A inscrição da imagem de um pequeno semelhante, um outro imaginário, como um modelo de identificação mimética possibilita a Donna encontrar um modo de sair do isolamento autístico e se relacionar com as pessoas, ainda que se apresente espelhada em outra pessoa. É através desta imagem unificada de Carol que Donna começa a construir um esboço de sua própria imagem corporal, e a posterior incorporação de Carol imaginária constitui a porta de entrada para uma mimetização generalizada que permite a Donna assumir diversos papéis-personagens através do potencial mimetizador da imagem de Carol. Carol concretiza uma "casca vazia de emoções” (Williams, 2012, p. 108), tornando-se um “frágil apoio" (p. 52), para "a única evasão possível para fora de minha prisão interior” (p. 52).

Carol vira a fachada que permite à Donna estabelecer contato com o mundo, mas ao preço da sua mutilação psíquica, da sua ausência subjetiva. O desaparecimento subjetivo de Donna concomitante com sua personificação via Carol permite, todavia, que Donna tenha um contato por 
procuração com a vitalidade espelhada em Carol e viabilize pontes com o mundo compartilhado.

Este papel de ego auxiliar da Carol imaginária pode ser evidenciado nas palavras da própria Donna: "Criei para mim um eu diferente daquele que estava travado e paralisado pelas emoções" (p. 52). Neste sentido, o espelhamento em Carol concretiza para Donna um importante papel de alienação a um outro e uma identificação que operacionaliza a construção de um esboço de imagem corporal, mimetizada no outro, e a possibilidade de utilizar, por procuração, da imagem do outro, apropriando-se de algumas características que lhe permitem a saída do isolamento autístico - principalmente características da motricidade, da habilidade social e da expressão verbal. Ao ver a imagem incorporada de outro, Donna adquiria a possibilidade de se apropriar de funções do corpo próprio e de construir uma imagem baseada no espelho-Carol. Deste modo, esta primeira etapa de espelhamento em Carol permite à Donna habitar o mundo, por procuração, alicerçada nesta identificação mimetizada.

\section{O surgimento do duplo imaginário Willie}

Antes de Carol, Donna, por volta de dois anos de idade, já havia inventado Willie. Nesta época, Donna tinha pavor de adormecer e dormia com os olhos abertos temendo que uma invasão inimiga a aniquilasse. Willie surge, então, presentificado, inicialmente, como dois grandes olhos verdes abertos que aparecem embaixo de sua cama, o que lhe promovia um sentimento de segurança e proteção. Os olhos se concretizam por bordas nas quais pode ser localizado o gozo que não encontrava localização no campo significante em decorrência da falta da identificação ao traço unário no autismo. Se por um lado, o surgimento de Willie permite uma localização parcial do gozo, é somente após a vivência do espelhamento mimético em Carol que Willie se concretiza em um duplo imaginário para Donna.

Willie se torna, então, o "guardião do corpo contra os intrusos" (Williams, 2012, p. 39), permitindo o contato com o mundo de forma defensiva. Willie protege Donna, possibilitando, assim, um contato com o mundo e consigo mesma. Além disso, por meio do espelhamento em Willie, Donna pode ter acesso às suas próprias experiências de vida como fatos objetivos sobre os quais pode pensar e refletir, o 
que nos remete a uma função de ego auxiliar de Willie.

Por meio da identificação mimética com Willie, Donna pode se lembrar de suas experiências de vida, desde que descarte a dimensão afetiva do vivido. Além disso, Willie está sempre no controle das vias de acesso ao mundo isolado de Donna e é ele quem personifica o administrador responsável por regular as suas saídas e entradas, assim como as áreas de compartilhamento e de pontes com o mundo das outras pessoas, o que nos remete à sua função egoica. Tudo deveria passar pelo crivo de Willie antes de atingir Donna e, desse modo, ele regula uma hipersensibilidade sensorial por meio da criação de barreiras psíquicas. Nisso reside a importância da mimetização egoicas, realizada através de Willie.

Enquanto a encarnação egoica em Carol permite a apropriação de uma imagem de corpo próprio espelhada em outro e a apropriação de funções corporais, a encarnação egoica em Willie permite à Donna a criação de barreiras psíquicas, a filtragem do que vem do mundo e a criação de mecanismos de defesa de proteção da integridade corporal e psíquica, além da capacidade de pensamento objetivo e de síntese.

O fato de essas funções serem realizadas por procuração, via os duplos, evidencia a necessidade de Donna, nesta etapa de espelhamento mimético, precisar manter tais características rejeitadas no duplo em uma 
"surdez ao [próprio] self"(Williams, 1994, p. 9) ou em uma "surdez interior"(p. 9). Somente lhe era possível viver o ressentido emocional, ecoado no outro, e viver em um corpo e habitar o mundo compartilhado, através da personificação nos seus duplos imaginários, egos auxiliares.

\section{A integração dos duplos imaginários e o surgimento do "eu"}

Willie e Carol personificam cada um deles partes de Donna que ela vivia, inicialmente, como independentes de si, tendo vida própria nos seus personagens. Willie e Carol fornecem a ponte de contato com o mundo, sua "encarnação exterior" (Williams, 2012, p. 39), através dos quais Donna pode estender cada vez mais pseudópodes em direção ao mundo exterior.

No entanto, via a presença no mundo por procuração, Donna só pode entrar em contato com o mundo, personificada em Carol e Willie. Nesta etapa, as suas partes rejeitadas - as emoções intensas, as raivas, os medos, as inseguranças, a vontade de ser amada pelos outros - são tratadas através de seus companheiros imaginários, permitindo-lhe viver por procuração estas características, ao mesmo tempo em que evitava a apropriação pessoal do que lhe produzia angústias intoleráveis.
Deste modo, se por um lado, a presença destes duplos se demonstra crucial para a existência de Donna durante algum tempo, por outro lado, o preço desta coexistência se torna, segundo Donna, "uma verdadeira mutilação psíquica” (Williams, 2012, p. 185-6) e o sentimento de perda de si mesma e de vazio.

Em casa eu passava horas diante do espelho, fixando meu olhar em meus próprios olhos. Ali, eu dizia baixinho e incansavelmente meu próprio nome. Tentava, às vezes, lembrar-me de quem eu era, mas ocorria-me também, para meu grande medo, perder a faculdade de me sentir eu própria (p. 108).

Donna descreve esta etapa de sua vida psíquica, na qual seus personagens se apropriaram de partes da sua subjetividade, como a sua casa de vidro com vidros invisíveis reforçados, que lhe permitiam o contato com o mundo, usando estas fachadas de si própria. Atrás destes personagens impenetráveis, entretanto, Donna escondia o que define como a sua ausência de self. A possibilidade de habitar a si mesma e o mundo, bem como a construção do seu eu necessitava ainda passar pelo obstáculo de seus companheiros imaginários, que carregavam fora dela as suas características rejeitadas.

A possibilidade de Donna poder se apropriar de suas características psíquicas rejeitadas e personificadas nos seus duplos tem como etapa preliminar a aproximação de seus duplos 
entre si. Willie e Carol, que foram originados como antíteses conflituosas um do outro, se aproximam um do outro quando surge um sentimento de simpatia pelos traços que o outro personifica. Nesta aproximação de Carol e Willie, é evidente o trabalho de construção egoica, de constituição das várias camadas do "eu", da acumulação das várias imagens mimetizadas de pequenos semelhantes, e da integração unificante das diversas identificações que vão construir o estofo egoico de Donna.

Via a aproximação dos personagens, Donna entra em contato com suas várias características espelhadas, que começam a ser reconhecidas como próprias, na medida em que ao invés de rejeitá-las, passa a ter por elas um sentimento de simpatia. Donna vive, dessa forma, uma maior integração de si mesma através de seus personagens, o que se concretizará com mais consistência quando ela pode reconhecer estes traços como próprios.

Após esta etapa de reconhecimento das próprias características, anteriormente rejeitadas nos personagens, Donna pode se despedir do apoio constante em seus personagens imaginários e dar boasvindas ao seu "eu", processo que Donna designa por "integração" (Williams, 1994, p. 101) de si mesma em um self. Abandonar esses personagens e se apropriar das características, que eles personificavam, lhe permite se entregar ao mundo sem as defesas propiciadas por seus duplos. É arriscar-se brutalmente em uma exposição sem a proteção dos vidros impenetráveis que protegiam a sua existência.

É interessante ressaltar que quando seus duplos se aproximam um de outro, aceitando-se mutuamente, Donna inventa um personagem Cachorro Travel que tinha a função de ser mais uma ponte entre o seu mundo e o das outras pessoas. Este personagem tinha um corpo, pois foi personificado em um boneco que Donna começou a carregar consigo e que trazia para ela a possibilidade de um conforto do mundo físico e a possibilidade de buscar nesta fronteira uma sensação de segurança. Além do companheiro de pelúcia Travel, Donna cria o Ursinho Orsi, que também se tornou uma ponte suplementar entre Donna e os outros. Ambos os bichinhos tinham uma dimensão de presença física no mundo externo e Donna se ligou afetivamente aos corpos dessas pelúcias encorpadas. Neste sentido, Donna apontava a importância de amar estes bichinhos de pelúcia a quem direcionava seus afetos, favorecendo seu sentimento de pertencimento a um mundo do qual Travel e Orsi fazem parte. 
Vale a pena apontarmos outro importante ponto mutativo que culminou com esta apropriação de si mesma e com a habitação do ser e do mundo. Concomitante com a despedida de seus personagens imaginários, Donna realiza um funeral simbólico da Carol real, em quem havia se espelhado e se apropriado de características que lhe permitiram uma forma de estar no mundo, mesmo que mimetizada em um outro.

A apropriação das características dos duplos aumenta a capacidade de Donna enfrentar situações que envolvem suportar emoções intensas, embora ainda lhe fosse um desafio intenso, o contato com o campo da afetividade. Donna desenvolve, então, estratégias para enfrentar o medo sem ter que fugir da situação e romper o laço com alguém querido que desperta uma emoção demasiadamente intensa. Com suas estratégias, Donna, em face dos imprevistos cotidianos, consegue conter a angústia inicial para, em seguida, procurar no próprio repertório de experiências caminhos que encontram ou inventam novas soluções para as situações angustiantes. O desenvolvimento destas formas de enfrentar o próprio medo implica um esforço deliberado para enfrentar as situações difíceis, sem "desaparecer” (Williams, 1994, p. 39) a sua vontade de viver a vida, não mais por procuração.

\section{A publicação do primeiro livro, a perda de uma parte de si própria e a possibilidade de se apropriar da imagem do corpo próprio, sem a necessidade do duplo imaginário}

Após se descolar dos seus duplos, Donna descreve a entrada em uma etapa de transição na qual não está mais sozinha no seu mundo isolado, mas ainda não encontrou seu lugar no mundo dos outros, não se sentindo ainda pertencendo ao mundo compartilhado.

Donna realiza, então, um passo decisivo ao escrever seu primeiro livro autobiográfico, remetendo tal esforço de elaboração a uma vontade de enfrentar os sentimentos e angústias que ela evitava e rejeitava e dos quais sempre fugia.

É para um amigo, Tim, em quem confia, que Donna entrega a primeira cópia do seu manuscrito terminado, em uma experiência tão intensa que Williams (1994) a equivale a uma automutilação. Tim 
já havia sido capaz anteriormente de atravessar a separação entre o mundo isolado de Donna e o mundo compartilhado que ela podia viver, quando junto dele, e após lhe dar esta parte de si mesma, do seu mundo, ela se olha no espelho e nota uma mudança: aparece uma vulnerabilidade em sua imagem, correlativa ao desaparecimento da fachada de Carol.

$\mathrm{Na}$ imagem refletida, não havia mais a morte, nem a faceta de Carol. Ao olhar a própria imagem no espelho, Donna é afetada, ao ver a si mesma. Esta imagem de si mesma refletida torna-se uma imagem companheira, que Donna descreve ser acompanhada pelo sentimento temporário de "familiaridade aditiva" (Williams, 1994, p. 13), por ela estar temporariamente "perdida nos olhos" (p. 14) de seu próprio reflexo no espelho.

Maleval (2009) aponta, nesta etapa, o investimento narcísico na imagem equivalendo às flores do estádio do espelho, traduzindo a possibilidade de Donna se olhar incluindo um brilho narcísico na imagem refletida. O estádio do espelho é um modelo teórico que nos permite figurar no escopo psicanalítico a constituição do eu e a origem do narcisismo em relação às incidências do imaginário e do simbólico nas identificações humanas. Há operações psíquicas em jogo no espelhamento humano em decorrência das quais a construção do "eu", a apreensão da imagem de si mesmo e do pequeno outro semelhante dependem da apropriação da própria imagem, via a imagem do outro. No autismo, há uma ausência desta identificação imaginária estruturante que precisa ser compensada através de invenções tais quais as inventadas por Donna. As flores ilustram, neste âmbito, a possibilidade da autoinvenção pelo autista de uma completude imaginária, do vaso com flores, que permitem ao autista se apreender através desta compensatória ilusão narcísica.

A publicação do livro equivale, desta forma, ao surgimento da imagem de um objeto narcísico que permite a alteração da relação com o próprio reflexo, uma apropriação de si e o surgimento do sentimento de ter um "eu". O livro publicado é um objeto cedido que permite uma compensação no campo imaginário, viabilizando a integração do seu reflexo no espelho real. O tratamento imaginário da perda do objeto cedido e a completude narcísica no espelho real ancoram, deste modo, na apropriação da imagem de si própria e na habitação do corpo próprio.

Além disso, conforme Maleval (2009) aponta com toda pertinência, o livro publicado possibilita a Donna se ler neste livro, 
público, o que lhe permite se perceber e ser percebida por um olhar distante direcionado a si mesma, à sua vida e às suas histórias, o que altera a sua apreensão de si mesma. Esta inscrição de um ponto de olhar outro (não Outro) no qual se espelhar, para além de si mesma e da sua imagem refletida são correlativas a uma alteração na economia de gozo, em que se inscrevem bordas neste ponto externo no qual o gozo se localiza.

A apropriação do corpo próprio possibilita para Donna a integração de suas partes rejeitadas nos seus duplos, a constituição de um "eu" através do reconhecimento da imagem própria no espelho e da perda de uma parte de si mesma por meio da publicação.

\section{O duplo Moggin e a possibilidade de afetar e ser afetada}

Donna também usa a sua própria imagem refletida como uma imagem real através da qual pode estudar as emoções, examinando sua imagem, por exemplo, tentando com ela estabelecer contato e, através da sua imagem, iniciar o toque em alguém, por exemplo, através do tocar sua própria imagem no espelho. Neste momento, o afetar e ser afetada diretamente no toque corporal direto, sem intermediação do espelho ainda lhe era, todavia, inacessível.
Através de um gatinho de pelúcia, puppet Moggin, Donna entra em contato com as pessoas, deixando-se tocar por procuração, em um primeiro momento. Acompanhada de Moggin, em um segundo momento, Donna pode iniciar o contato com pessoas próximas por quem ela tem carinho e a quem ela gostaria de tocar. Sente que quer afetar e ser afetada por pessoas importantes na sua vida com quem já estabeleceu um laço de confiança e segurança. Em uma situação específica em que cria um espelhamento de mãos com uma amiga, tendo Moggi junto para lhe dar o sentimento de proteção, Donna, ao observar as duas imagens ao mesmo tempo, ela e a amiga cada uma interagindo com a própria imagem, dá-se conta da distinção entre a imagem de si própria e a imagem da amiga, mas ainda tem dificuldade para perceber a imagem como um reflexo da pessoa.

Após se entregar a experiências de ser tocada diretamente por outros humanos que lhe são de confiança, sem ter que passar pela intermediação de um espelho real, Donna se olha no espelho e vê uma fragilidade na sua imagem refletida. Esta experiência de contato com a vulnerabilidade, podendo ser afetada por outros humanos, permite à Donna se sentir feliz consigo mesma, vendo-se colorida em contato com as emoções. Em uma situação específica, após vivenciar um intenso afeto em um encontro em que pode 
ter seu corpo tocado e afetado sem se dissociar, Donna vai para a sua casa, faz inúmeros desenhos coloridos, incluindo um desenho de sete gatos, que são para ela importantes imagens de si mesma, coloridos como um arco-íris, figurando o que designa como “o espectro das emoções" (Williams, 1994, p. 125).

Donna relata a sua felicidade, ao se sentir "real" (Williams, 1994, p. 149), propiciada pela possibilidade de ser afetada pelos outros e pela experiência de sentir emoções em relação às sensações do próprio corpo. Neste sentido, ela aponta a distância entre imitar a face ou o comportamento correspondente ao que uma pessoa sentiria, e a possibilidade de viver no próprio corpo uma emoção e de conseguir nomear como uma emoção afetou seu corpo. Tal vivência lhe origina o sentimento de pertencimento ao mundo, concomitante com a apropriação, parcial, do campo da afetividade. A possibilidade de ser afetada teve de ser construída por Donna e tal processo é imbricado à construção de seu estofo imaginário, pois ser afetado e poder se apropriar do corpo próprio têm relação com o campo imaginário para o ser humano.

\section{O investimento narcísico após a publicação do segundo livro}

Em sua segunda autobiografia, já ancorada em um estofo imaginário compensatório, Donna vê uma imagem narcísica de si mesma, apaixonando-se pela própria imagem refletida, na qual pode se ver florida, sentindo-se em casa, consigo mesma.

Maleval (2009) aponta que nas descrições do espelho feitas neste livro emergem flores e imagens floridas que se concretizam como um objeto a mais, separado do reflexo e que não pode ser reduzido à imagem de si mesmo. As flores - objetos narcísicos - originam uma completude imaginária. O ego e a imagem do corpo próprio podem ser narcisados por flores e Donna pode, então, olhar-se de um ponto que escapa do reflexo, via o seu livro. O livro não é um espelho via o Outro, mas permite a unificação da imagem do corpo e o investimento narcísico desta.

Logo após a decisão de escrever o segundo livro, Donna é tomada pelo sentimento de pertencimento do seu corpo, da ancoragem no interior de si mesma das partes do seu corpo, concomitantemente com o sentimento de extimidade, de que o mais íntimo de si mesma é estrangeiro. Maleval (2009) sugere que esta emergência do estrangeiro na apreensão de si mesma, no espelhamento, é correlativa ao gozo que agora pode ser vivido marcando o corpo próprio e não precisa 
mais ser totalmente rejeitado, embora não seja possível a inscrição do gozo no corpo via o significante (alíngua) em decorrência da não incorporação do traço unário na estrutura autística.

Ainda que o espelhamento de Donna seja a construção de um espelho real, e não virtual, ele lhe possibilita a construção de um estofo imaginário e, após ganhar a consistência imaginária através do surgimento da imagem unificada de si própria, da construção egoica e da possibilidade de habitar a si própria e o mundo, Donna pode se aproximar do campo da afetividade. Mesmo tendo que manter o controle para se conectar e se desconectar de emoções intensas, ela pode se permitir afetar e ser afetada por outros humanos, entrando em contato diretamente com a dimensão de gozo do corpo, o que lhe dá o sentimento de ser real, de poder ser tocada no íntimo do seu ser por outros humanos.

Em decorrência da falta da ancoragem do traço unário no corpo, não há a crochetagem das marcas primordiais do Outro e nem a construção das bordas pulsionais a partir destas marcas do significante (alíngua), mas Donna concretiza uma alienação imaginária aos seus duplos que lhe permite se apropriar de seu corpo, construir sua imagem de corpo próprio e seu "eu".

\section{Conclusão}

O percurso de Donna demonstra a possibilidade de o autista compensar, parcialmente, no campo imaginário, as consequências da não alienação plena ao significante primordial, podendo tecer um estofo imaginário que lhe permita construir um ego, apropriar-se do corpo próprio, obter uma imagem de si mesmo, sentir-se real, habitar o mundo e viver a vida de uma maneira mais livre.

A leitura das autobiografias de Donna são relatos contundentes sobre os efeitos terapêuticos que os duplos podem exercer para os autistas, sinalizando a importância destas invenções autoterapêuticas serem valorizadas na condução do tratamento pelo psicanalista. Podemos concluir enfatizando a importância da contribuição da abordagem psicanalítica para o estudo da relevância terapêutica dos duplos no autismo enquanto invenções singulares que permitem imprescindíveis compensações no campo imaginário, tal qual evidenciamos em Donna. 
THE SUPPORT OF THE AUTISTIC DOUBLE IN THE CONSTRUCTION OF THE IMAGINARY IN AUTISM

\section{Abstract}

This paper focuses on the construction of compensatory identifications with the autistic double that shall allow the autistic to construct an imaginary padding. Through Donna Williams, we address mirroring and identification with imaginary doubles as pillars of the constitution of body image, the emergence of narcissism and the construction of an ego in autism.

Index terms: psychoanalysis; autism; double; imaginary; ego.

EL APOYO DEL DOBLE AUTÍSTICO EN LA CONSTRUCCIÓN DEL IMAGINARIO PARA EL AUTISMO

\section{RESUMEN}

Este artículo se centra en la construcción de identificaciones compensatorias con el doble autístico que pueden permitir al autista la construcción de una protección imaginaria. Se abordan a través de Donna Williams el espejo y la identificación con los dobles como los pilares para la constitución de una imagen del propio cuerpo, del surgimiento del narcisismo y de la construcción de un ego en el autismo.

Palabras clave: psicoanálisis; autismo; doble; imaginario; ego.

\section{REFERÊNCIAS}

Bialer, M. (2012). Le corps dans l'autisme et dans la schizophrénie (Tese de doutorado). École doctorale Recherches en psychanalyse/Instituto de Psicologia, Université Paris 7 Denis Diderot/Universidade de São Paulo, Paris/São Paulo.

Frayssinet, M. (2012). Autisme et schizophrénie (Tese de Doutorado). École doctorale Recherches en psychopathologie, Université Rennes 2, Rennes.

Laurent, E. (2010). Les futurs des spectres de l'autisme. In B. Halleux (Org.), Quelque 
chose à dire à l'enfant autiste: pratique à plusieurs à l'Antenne 110 (pp. 223-236). Paris: Éditions Michèle.

Maleval, J-C. (2009). L'autiste et sa voix. Paris: Éditions du Seuil.

Williams, D. (1994). Somebody Somewhere: breaking free from the world of autism. Nova York: Three Rivers Press.

Williams, D. (2012). Meu mundo misterioso: testemunho excepcional de uma jovem autista. Brasília: Thesaurus.

mbialer@hotmail.com

Rua Dr. Homem de Melo, 407/71

05007-001 - São Paulo - SP - Brasil.

Recebido em outubro/2013. Aceito em maio/2014. 